\title{
Compostagem dos resíduos orgânicos em instituições de ensino: experiências do IFCE - Campus Juazeiro Do Norte
}

\section{Composition of the organic waste in teaching institutions: case study in the IFCE - Campus Juazeiro Do Norte}

Joelma Lima Oliveira a

Ana Beatriz Batista de Almeida ${ }^{b}$

Letícia Lacerda Freire $^{c}$

Monique da Silva Albuquerque ${ }^{d}$ Janderson Cabral Barbosa Mailodovinci de Sousa Pereira ${ }^{\dagger}$

Uriel Pereira da Silva Barbosa ${ }^{9}$

\begin{abstract}
a Instituto Federal de Educação, Ciência e Tecnologia do Ceará - Campus Juazeiro do Norte. Docente do Curso de Bacharelado em Engenharia Ambiental; Tecnóloga em Saneamento Ambiental; Mestra em Engenharia Civil. E-mail: joelma.oliveira@ifce.edu.br
\end{abstract}

b Instituto Federal de Educação, Ciência e Tecnologia do Ceará - Campus Juazeiro do Norte. Discente do Curso de Bacharelado em Engenharia Ambiental. E-mail: almeidabeatriz993@gmail.com

c Bacharel em Engenharia Ambiental e Sanitária pelo Instituto Federal de Educação, Ciência e Tecnologia do Ceará - Campus Juazeiro do Norte; Técnica de Laboratório em Meio Ambiente do IFCE - Campus Sobral. Email: leticia.freire@ifce.edu.br

d Instituto Federal de Educação, Ciência e Tecnologia do Ceará - Campus Juazeiro do Norte. Discente do Curso de Bacharelado em Engenharia Ambiental. E-mail: monique.albuquerque1996@gmail.com

e Instituto Federal de Educação, Ciência e Tecnologia do Ceará - Campus Juazeiro do Norte. Discente do Curso de Bacharelado em Engenharia Ambiental. E-mail: j.anderson.cabral1@gmail.com

Ciência e Sustentabilidade - CeS / Juazeiro do Norte v. 4, n. 1, p. 57-78, jan/jun 2018 I ISSN 2447-4606 
† Instituto Federal de Educação, Ciência e Tecnologia do Ceará - Campus Juazeiro do Norte. Discente do Curso de Bacharelado em Engenharia Ambiental. E-mail: mailodovinc@gmail.com

g Instituto Federal de Educação, Ciência e Tecnologia do Ceará - Campus Juazeiro do Norte. Discente do Curso de Bacharelado em Engenharia Ambiental. E-mail: urielbarbosa46@gmail.com

Recebido em: 18/05/2018 I Aceito em: 25/06/2018

ARTIGO

\section{RESUMO}

No Brasil são gerados diariamente percentuais representativos de resíduos orgânicos, majoritariamente dispostos de maneira irregular. Uma forma de destinação final recomendada pela Política Nacional dos Resíduos Sólidos é a compostagem, um processo aeróbio de conversão da matéria orgânica em um composto estável que pode ser utilizado para enriquecer o solo. Neste trabalho, apresentamos o sistema de compostagem por leiras aeradas adotado pelo Instituto Federal do Ceará (IFCE) - Campus Juazeiro do Norte. O mecanismo adotado possui controle das condições diárias de umidade, verificação dos valores de temperaturas interna, superficial e ambiente. Semanalmente, são verificados valores de $\mathrm{pH}$ e da relação Carbono/Nitrogênio para o composto final. Apresentamos uma análise da logística de implantação, considerando as etapas de separação, coleta, transporte, processamento e destinação do adubo para as áreas verdes do Campus. Foram discutidas as etapas de implantação, onde foi adotado o método do Plan-Do-CheckAct para esquematização das ações. Verificou-se consonância com a literatura das medidas de variações de temperatura e ph com as fases de digestão típicas da compostagem. Uma das leiras sofreu desequilíbrios na etapa de processamento, devido à umidade excessiva adquirida no período chuvoso, requerendo maior atenção e manobras operacionais. O composto produzido apresentou boas condições da relação Carbono/Nitrogênio, compatível com o relatado por Kiehl (1998). Os principais desafios foram verificados na aquisição de materiais, nos procedimentos de continuidade e na inserção das práticas requeridas no regime funcional da instituição.

Palavras-chave: Resíduos Orgânicos. Gestão Ambiental. Compostagem. 


\section{ABSTRACT}

In Brazil, representative percentages of organic waste are generated daily, the most of them irregularly arranged. A final disposal recommended by the National Solid Waste Policy is the composting, an aerobic process of converting organic matter into a stable compound that can be used to enrich the soil. In this work, we present the composting system for aerated furrow adopted by the Instituto Federal do Ceará (IFCE) - Campus Juazeiro do Norte. The mechanism adopted has daily control of internal moisture condition, surface and ambient temperature. Once a week, the $\mathrm{pH}$ value and the Carbon/Nitrogen measure for the final compound are verified. We present an analysis of the implantation logistics, considering the steps of separation, collection, transportation, processing and destination of the fertilizer to the green areas of the Campus. The stages of implementation were discussed, where the PlanDo-Check-Act method was adopted for the schematization of actions. We verify consistency with the literature on the measures of the temperature and ph variations for the typical composting digestion phases. One of the furrows suffered imbalances in the processing stage, due to the excessive moisture acquired during the rainy season, requiring more attention and operational maneuvers. The compound produced presented good conditions of the Carbon/Nitrogen ratio, within the range recommended in the literature. The main obstacles were verified in the acquisition of materials and in the procedures of continuity and insertion of the practices required in the functional regime of the institution.

Key-Words: Organic waste. Environmental Management. Composting.

\section{INTRODUÇÃO}

Notadamente, um grande percentual dos resíduos sólidos gerados no Brasil é composto da fração de orgânicos. Segundo o Ministério do Meio Ambiente (BRASIL, 2017), aproximadamente 50\% dos Resíduos Sólidos Urbanos (RSU) gerados no país são orgânicos e poderiam ter como alternativa de destinação final ambientalmente adequada o tratamento por processos aeróbios de compostagem.

De acordo com a Política Nacional de Resíduos Sólidos, a Lei 12.305/2010, as responsabilidades pelo gerenciamento do processo de compostagem devem ser divididas entre os órgãos de limpeza pública urbana e as empresas de manejo de resíduos, conforme prescrito no Plano Municipal de Gestão Integrada de Resíduos Sólidos de cada unidade administrativa. As entidades geradoras também ficam incumbidas de definir o emprego dado ao composto orgânico resultante. Cabe destacar ainda que todo programa de gestão e gerenciamento deve contemplar a seguinte ordem de prioridade: não geração, redução, reutilização, reciclagem, 
tratamento dos resíduos sólidos e disposição final ambientalmente adequada dos rejeitos (BRASIL, 2010).

Implantar a compostagem dos resíduos orgânicos está entre os objetivos principais do Plano Estadual dos Resíduos Sólidos do Ceará (2015), assim como é indicada para as políticas ambientais dos municípios. Em geral, a produção de resíduos em uma localidade ocorre em grande escala, pois além do quantitativo gerado pelas residências, há os resíduos de poda da limpeza urbana e dos mercados públicos. Isto configura um retorno representativo da produção de um composto para a aplicação no solo, o que pode favorecer a geração de renda ou subsidiar demandas municipais na manutenção das áreas verdes.

As Instituições de Ensino Superior (IES) podem ser consideradas grandes geradoras de RSU, em consequência das atividades praticadas. Somado a isso, possuem a responsabilidade de qualificar e conscientizar os cidadãos formadores de opinião, devendo desenvolver práticas que auxiliem neste processo. Assim, as IES lançam meio de iniciativas de gestão ambiental para reduzir os impactos ambientais decorrentes das suas atividades, cumprindo com a legislação vigente e servindo de suporte para o desenvolvimento do pensamento sustentável (TAUCHEN \& BRANDLI, 2006).

Experiências exitosas apontam a compostagem como uma prática com viabilidade de implantação para a destinação dos resíduos orgânicos. $\mathrm{Na}$ Universidade Federal de Santa Catarina são tratadas em média 64 toneladas de resíduos orgânicos por mês (JULIATTO, CALVO e CARDODO, 2011). Outras instituições também têm optado pela implantação da técnica, como o Campus II da Pontifica Universidade Católica - PUC Goiás (MALHEIROS et al., 2004), o Instituto Federal da Paraíba - IFPB (ANDRADE, 2018), a Universidade Estadual da Paraíba UEPB (SILVA e TAVARES, 2018). Propalar experiências embasadas na logística de uma composteira de escala real, pode fomentar a adoção desta por outras instituições.

Neste contexto, o Instituto Federal de Educação, Ciência e Tecnologia do Ceará - IFCE, Campus Juazeiro do Norte, ciente das suas responsabilidades como IES, adotou o processo de compostagem para os resíduos orgânicos oriundos do Restaurante Acadêmico (RA) da instituição, além de promover a conscientização Ciência e Sustentabilidade - CeS / Juazeiro do Norte, v. 4, n. 1, p. 57-78, jan/jun - 2018 
ambiental da comunidade acadêmica. Posto isto, o presente trabalho tem como objetivo apresentar os resultados do acompanhamento do processo de implantação e da fase operacional da referida composteira.

\section{METODOLOGIA}

\subsection{Tipologia da pesquisa e população envolvida}

A organização metodológica de obtenção e discussão dos dados utilizados pode classificar este trabalho como um estudo de caso de caráter exploratório acerca da viabilidade de implantação de uma composteira em instituições de ensino superior, com base nas experiências vivenciadas no Instituto Federal de Educação, Ciência e Tecnologia do Ceará - IFCE Campus Juazeiro do Norte, o qual possui atualmente 484 alunos matriculados nos cursos técnicos com ensino médio integrado, 1.728 nos cursos de graduação e 16 em pós-graduação. A instituição possui um restaurante acadêmico, do qual são destinados os resíduos para a composteira.

\subsection{Sistemas de Compostagem}

De acordo com a NBR 13.591/1996 a compostagem pode ser definida como um "processo de decomposição biológica da fração orgânica biodegradável dos resíduos, efetuado por uma população diversificada de organismos, em condições controladas de aerobiose e demais parâmetros (...)".

O processo de compostagem tem como produto resultante um adubo orgânico que pode ser empregado para enriquecer o solo. Somado a isto, a técnica possibilita o aumento da vida útil dos aterros sanitários, por evitar o envio dos resíduos orgânicos ao local. (OLIVEIRA et al., 2008).

É possível classificar os sistemas de compostagem em três tipologias: o sistema de leiras revolvidas (Windrow), o de leiras estáticas aeradas (Static pile) e os sistemas fechados ou reatores biológicos (In-vessel). O sistema de leiras 
revolvidas se destaca pela simplicidade operacional, cujo revolvimento pode ser manual ou mecanizado. (FERNANDES E SILVA, 1999)

A metodologia adotada pelo IFCE - Campus Juazeiro do Norte consistiu em leiras revolvidas (Windrow), por não apresentar custos elevados de manutenção e operação, assim como por ser um sistema mais flexível, tendo em vista a variação do quantitativo de geração de resíduos.

Destaca-se que o bom resultado nos processos de decomposição depende do controle das condições de alguns parâmetros como $\mathrm{pH}$, temperatura, umidade, relação Carbono/Nitrogênio (C:N), aeração e granulometria. Esses promovem um meio equilibrado para favorecer a atividade microbiana.

\subsection{Logística do Processo}

A implantação do sistema de compostagem foi uma iniciativa do Setor de Resíduos Sólidos do Sistema de Gestão Ambiental (SGA) da Instituição. O grupo ficou responsável por realizar projetos que visavam a redução dos resíduos sólidos dentro do Campus e alternativas de tratamento e disposição final destes.

Os resíduos sólidos recicláveis são destinados para uma associação de catadores de materiais recicláveis, conforme recomendado pelo Decreto 5.940/2006. Os resíduos orgânicos são encaminhados para o pátio de compostagem, situado nas imediações da Instituição e monitorado pelo Núcleo de Gestão Ambiental composto por docentes, técnicos administrativos e discentes do curso de Bacharelado em Engenharia Ambiental.

Para que fosse seguida a metodologia estabelecida nas atividades do SGA, as ações foram esquematizadas com base nas etapas do ciclo PDCA (Plan, Do, Check, Action), indicado pelos protocolos de normatização internacional da International Organization for Standardization (ISO), em sua série 14001/2015. A sequência de ações em cada etapa de trabalho é apresentada na Figura 01. 
Joelma Lima Oliveira; Ana Beatriz Batista de Almeida;

Letícia Lacerda Freire; Monique da Silva Albuquerque; Janderson Cabral Barbosa;

Mailodovinci de Sousa Pereira;

Uriel Pereira da Silva Barbosa

Figura 01 - Logística da compostagem no IFCE - Campus Juazeiro do Norte.

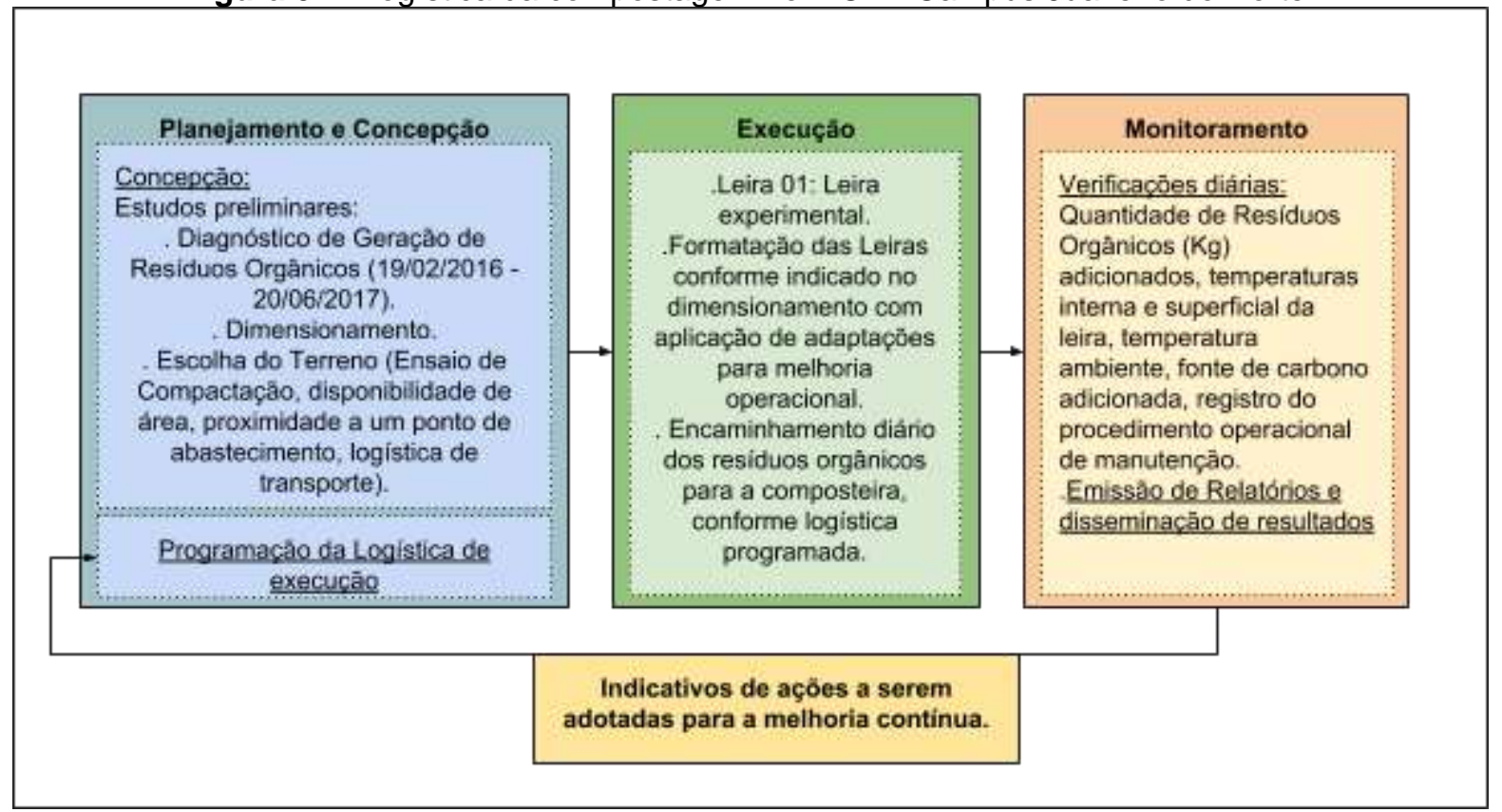

Os parâmetros verificados em cada etapa e as suas referidas metodologias analíticas estão apresentados no Quadro 01.

Quadro 01 - Parâmetros e métodos.

\begin{tabular}{|c|c|c|c|c|}
\hline \multirow{2}{*}{ Parâmetro } & \multicolumn{2}{|c|}{ Método / Referência } & \multicolumn{3}{c|}{ Etapa } \\
\cline { 3 - 5 } & & Plan & Do & Check \\
\hline Ensaio de Compactação do Solo & Proctor Normal (NBR 7.182/1986) & $\mathrm{x}$ & & \\
\hline $\begin{array}{c}\text { Densidade dos Resíduos } \\
\text { Orgânicos }\end{array}$ & $\begin{array}{c}\text { Relação massa por volume aferidos } \\
\text { durante cinco dias de geração dos } \\
\text { resíduos orgânicos. }\end{array}$ & $\mathrm{x}$ & & \\
\hline Temperatura & Medição direta & & $\mathrm{x}$ & $\mathrm{x}$ \\
\hline pH & Medição direta & & $\mathrm{x}$ & $\mathrm{x}$ \\
\hline Teste de Umidade & "Teste da mão" (EMBRAPA, 2009) & & $\mathrm{x}$ & $\mathrm{x}$ \\
\hline Nitrogênio & Nitrogênio Total Kjeldahl (Kiehl, 2011) & & & $\mathrm{x}$ \\
\hline Carbono Orgânico Total & Gravimétrico (EMBRAPA, 2011)** & & & $\mathrm{x}$ \\
\hline
\end{tabular}

${ }^{*}$ Circular Técnico da Embrapa, publicado por NUNES (2009)

${ }^{* *}$ Manual da EMBRAPA organizado por Donagema et al. (2011) 
Os estudos preliminares quanto ao diagnóstico de resíduos sólidos orgânicos foram realizados em parceria com a administração do Campus, a partir das pesagens diárias dos resíduos gerados pelo RA no ano de 2016, disponíveis em registro eletrônico da instituição. Anteriormente a esse período, a Instituição já fornecia refeições, com exceção ao almoço, e já havia uma geração considerável de resíduos orgânicos, no entanto, ainda não mensurados com a pesagem. Os dados de geração dos resíduos, reunidos para a concepção da composteira, estão dispostos na Figura 02.

Figura 02 - Resíduos orgânicos gerados pelo RA entre Fevereiro de 2016 e Junho de 2017.

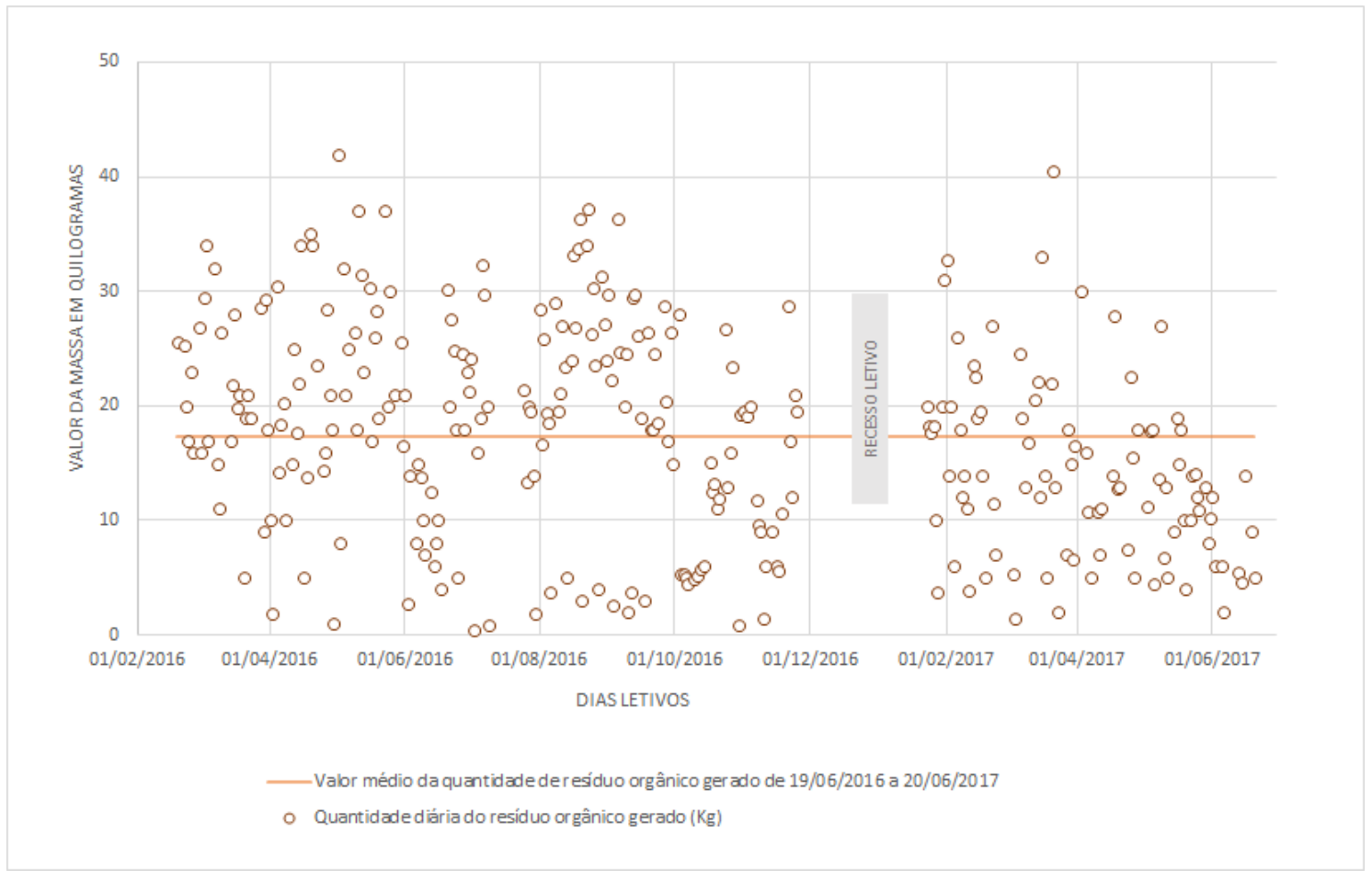

No dimensionamento da composteira foi necessário estabelecer parâmetros decisivos para determinar a área total demandada pelo sistema, de modo que viabilizasse sua implantação, operação e manutenção. A Empresa Brasileira de Pesquisa Agropecuária - EMBRAPA (2009) apresentou recomendações, como a necessidade da declividade das leiras entre $2 \%$ a $3 \%$, o tempo de processamento de 90 a 120 dias e altura da leira de 1,0 a 1,5 metro. Além disso, há recomendações quanto à geometria da leira, sendo indicada a adoção de seções transversais trapezoidais para os períodos e/ou regiões mais secas, por apresentar maior Ciência e Sustentabilidade - CeS / Juazeiro do Norte, v. 4, n. 1, p. 57-78, jan/jun - 2018 
Joelma Lima Oliveira; Ana Beatriz Batista de Almeida;

Letícia Lacerda Freire; Monique da Silva Albuquerque;

Janderson Cabral Barbosa;

Mailodovinci de Sousa Pereira;

Uriel Pereira da Silva Barbosa

retenção da umidade; e as piramidais em períodos chuvosos, por possuir uma menor área de captação de água e proporcionar o escoamento com maior facilidade.

Fez-se necessário ainda considerar a área para o revolvimento das leiras, o espaço de transporte dos materiais e para a ocorrência de eventualidades operacionais. Destaca-se que a determinação da área necessária depende do volume do material a ser compostado e das conformações geométricas selecionadas.

Os resultados do dimensionamento, conforme a situação descrita para cada uma das formatações geométricas segue indicados na Tabela 02.

Tabela 02 - Valores dos parâmetros de dimensionamento

\begin{tabular}{lll}
\hline Parâmetros & Geometria das leiras & \\
& Piramidal & Trapezoidal \\
Densidade do resíduo $\left(\right.$ ton $\left./ \mathrm{m}^{3}\right)$ & 1,06 & 1,06 \\
Volume diário de resíduo $\left(\mathrm{m}^{3}\right)$ & 0,016 & 0,016 \\
Volume de resíduo por leira $\left(\mathrm{m}^{3}\right)$ & 0,2250 & 0,3375 \\
Altura da leira $(\mathrm{m})$ & 1 & 1 \\
Largura da leira $(\mathrm{m})$ & 1 & 1 \\
Base menor $(\mathrm{m})$ & - & 0,50 \\
Seção da leira $(\mathrm{m})$ & 0,50 & 0,75 \\
Comprimento da leira $(\mathrm{m})$ & 1,5 & 1,5 \\
Área da base $\left(\mathrm{m}^{2}\right)$ & 3 & 3 \\
Volume estimado por leira $\left(\mathrm{m}^{3}\right)$ & 0,750 & 1,125 \\
Tempos de maturação $($ dias $)$ & 120 & 120 \\
Número de leiras & 8 & 5 \\
Área ocupada $\left(\mathrm{m}^{2}\right)$ & 23 & 15 \\
Tempos de preenchimento $($ dias $)$ & 14 & 21
\end{tabular}

No tocante à escolha da área de implantação mais adequada para a composteira, foi avaliada a disponibilidade de área em relação a demandada, a proximidade com uma fonte de abastecimento de água e com a destinação dos resíduos de podas da jardinagem, já anteriormente realizada nas atividades de manutenção. Para o reconhecimento da necessidade de impermeabilização, 
realizou-se um ensaio de compactação do solo, de acordo com a NBR 7182/2016, onde o mesmo foi caracterizado com elevado grau de compactação.

Após a finalização da etapa de dimensionamento da área de compostagem e das leiras necessárias para acomodar diariamente o resíduo orgânico oriundo das atividades do Restaurante, foi iniciada a fase de operacionalização do sistema, em 17 de Outubro de 2017.

Durante a fase inicial de operação foi necessário selecionar o trajeto que possuía o menor fluxo de pessoas para não gerar importunos à comunidade acadêmica. A distância a ser percorrida foi otimizada, mas houve a necessidade de substituição dos baldes de transporte por uma carriola, item esse já previamente sugerido no projeto da composteira.

Para o acompanhamento dos processos de decomposição da matéria orgânica no sistema de compostagem adotado, foi realizado o monitoramento de parâmetros de umidade, temperatura, $\mathrm{pH}$ e relação $\mathrm{C}: \mathrm{N}$.

A umidade e a temperatura foram verificadas diariamente, para essa última considerou-se as medidas de temperatura interna, externa e ambiente. A partir destes valores, foi verificada a necessidade de revolvimento para cada leira. $\mathrm{O} p H$ foi medido semanalmente, de forma a acompanhar qualquer alteração brusca do sistema. A relação $\mathrm{C}: \mathrm{N}$ foi analisada apenas para o composto final, no intuito de verificar a qualidade do mesmo.

\section{RESULTADOS E DISCUSSÕES}

\subsection{Planejamento e Concepção}

A partir dos valores apresentados na Figura 02, é possível observar que há uma tendência de redução do volume desperdiçado em relação ao valor médio verificado de 17,26 Kg/dia. Isso pode ser justificado pelas iniciativas de educação ambiental realizadas pela administração do RA, informando o quantitativo de desperdício frente ao alarmante número de pessoas sem acesso a uma alimentação de qualidade.

Ciência e Sustentabilidade - CeS / Juazeiro do Norte, v. 4, n. 1, p. 57-78, jan/jun - 2018 
Os resíduos a serem compostados são as sobras de alimentos cozidos e crus, com elevada densidade $\left(1,06 \mathrm{ton} / \mathrm{m}^{3}\right)$ e umidade, conforme apresentado na Figura 03. Os resíduos oleosos de carnes são separados no momento do descarte pelos usuários do Restaurante, por meio de recipientes seletivos sinalizados sendo enviados a coleta de resíduos municipal.

O odor característico, em especial dos resíduos de carne, e o potencial de formação de uma camada hidrofóbica que dificulta a digestão do resíduo orgânico pelos microrganismos foram os principais fatores para a não inserção dos resíduos oleosos no sistema de compostagem.

Figura 03 - Resíduo orgânico amostral gerado no RA.

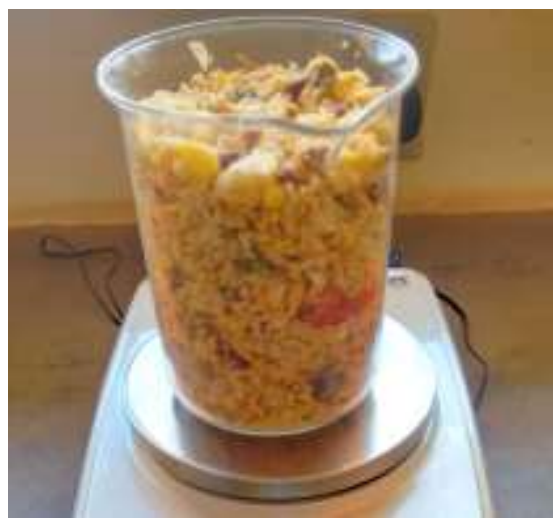

\subsection{Logística Programada de Execução Inicial}

A partir dos diagnósticos realizados, foi proposta uma logística de gerenciamento dos resíduos orgânicos, de modo que este pudesse subsidiar as demandas do Campus. As etapas de gerenciamento do resíduo e destinação do composto produzido foram esquematizadas na Figura 04.

Figura 04 - Etapas de gerenciamento dos resíduos orgânicos. 


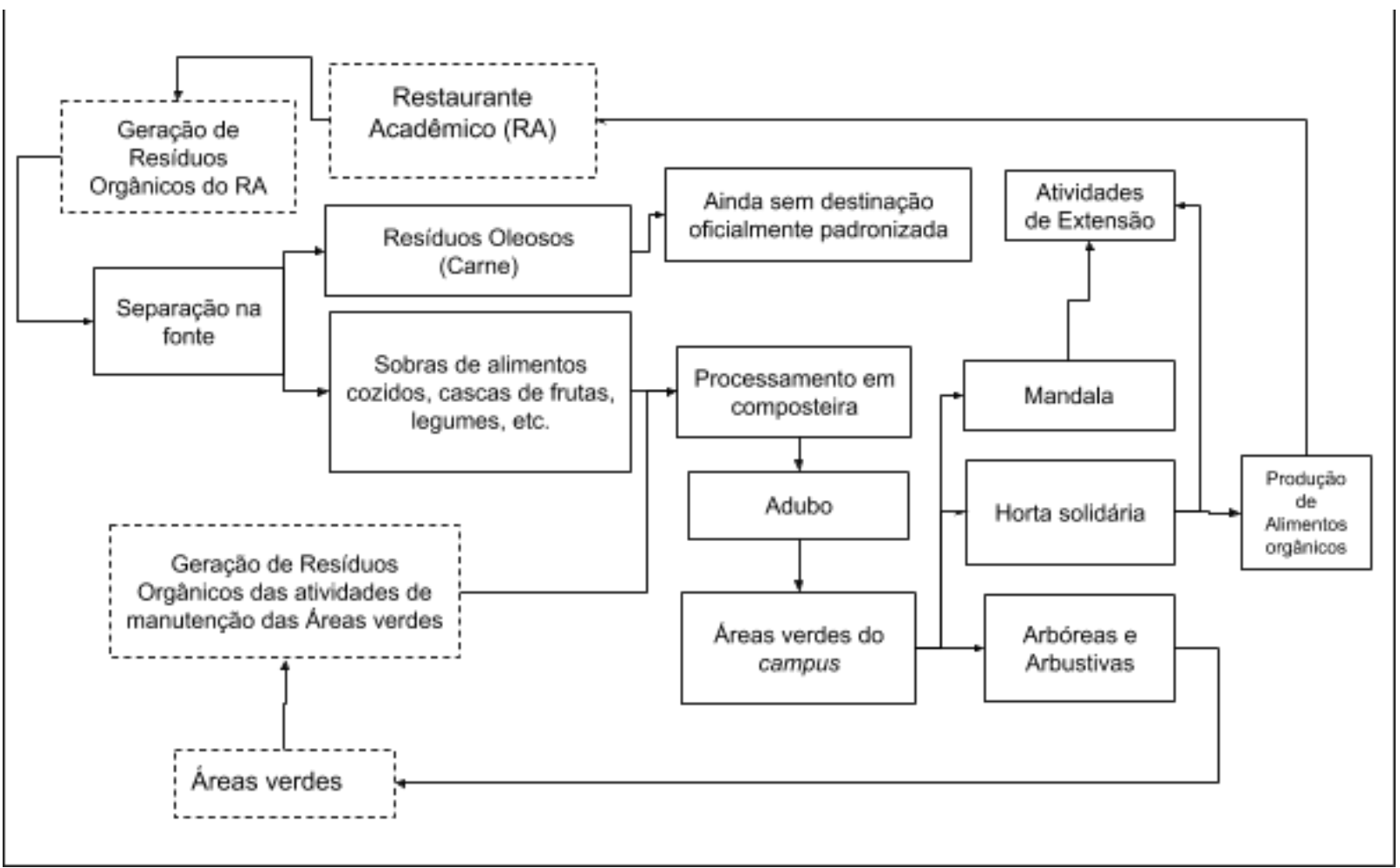

A partir da operacionalização do sistema foi possível observar a potencialidade de integração entre a geração e a destinação do composto final com as atividades do Campus. A principal destinação do adubo produzido consiste no uso para a manutenção de áreas verdes, destacando as doações para a horta solidária, a qual produz hortaliças e outras culturas direcionadas para RA e para consumo dos colaboradores. Outro local de encaminhamento estratégico seria o projeto Mandala, um sistema produtivo que serve de campo experimental de cultivo e é utilizado em atividades de ensino, pesquisa e extensão.

\subsection{Análise dos dados de Monitoramento}

\subsubsection{Dados de monitoramento da Leira 01}

Um dos indicadores entre as etapas de decomposição ativa, humificação e maturação é a temperatura. A partir de sua determinação foi possível acompanhar a velocidade da atividade metabólica dos microrganismos e verificar um indicativo da chegada a etapa de humificação. 
Joelma Lima Oliveira; Ana Beatriz Batista de Almeida;

Letícia Lacerda Freire; Monique da Silva Albuquerque;

Janderson Cabral Barbosa;

Mailodovinci de Sousa Pereira;

Uriel Pereira da Silva Barbosa

A leira experimental 01 foi iniciada no dia 17 de outubro de 2017 e teve a sua etapa de maturação concluída em 22 de dezembro do mesmo ano, após decorridos 66 dias. A fase termófila alcançou uma temperatura interna máxima de $67^{\circ} \mathrm{C}$.

Sobrinho et al. (2017) analisando a compostagem de resíduos orgânicos de um restaurante acadêmico, com leira de seção transversal trapezoidal (altura $=2 \mathrm{~m}$, comprimento $=1,5 \mathrm{~m}$ e largura $=1,5 \mathrm{~m}$ ), verificou o início da fase termófila a partir do oitavo dia de processamento, com uma temperatura máxima de $70^{\circ} \mathrm{C}$. Em seus ensaios essa fase ocorreu em 21 dias, com maturação em cerca de 70 dias.

Reduções na temperatura podem indicar que a velocidade de degradação do composto foi alterada, podendo ser ocasionada por desajustes de aeração, umidade ou em decorrência do balanço de nutrientes; enquanto que temperaturas elevadas, superiores a $75^{\circ} \mathrm{C}$, representam a necessidade de revolvimento, tendo em vista que pode haver a morte demasiada de microrganismos, prejudicando a continuidade do processo de digestão e humificação (HEBERT et al., 2005).

Realizou-se o monitoramento do $\mathrm{pH}$ da leira 01, de forma a analisar em que fase estava a decomposição da matéria orgânica. Os valores de pH estão elencados na Tabela 03.

Tabela 03 - Dados de pH para a Leira 01

$\begin{array}{cc}\text { Período } & \text { pH } \\ 27 \mathrm{nov} / 17 \text { a } 01 \mathrm{dez} / 17 & 7,01 \\ 04 \mathrm{dez} / 17 \text { a } 08 \mathrm{dez} / 17 & 7,02 \\ 18 \mathrm{dez} / 17 \text { a } 22 \mathrm{dez} / 17 & 7,81\end{array}$

A leira 01 foi implantada como um modelo piloto para que os colaboradores do Setor de Resíduos Sólidos aprendessem a técnica de compostagem. Nesse período, por não possuírem conhecimento prático e domínio no manuseio dos materiais e equipamentos necessários, o acompanhamento dos parâmetros deu-se de forma tardia ao início de operação da leira.

Somente na quinta semana de operação, foi iniciado o monitoramento de $\mathrm{pH}$ onde observou-se permanência dos valores na faixa da neutralidade. Nos processos de compostagem a fase inicial tende a ser ácida, pela produção de $\mathrm{CO}_{2}$. No entanto, 
com a continuidade da digestão e degradação da matéria orgânica esses compostos são convertidos às formas alcalinas, elevando o $\mathrm{pH}$.

Os valores obtidos após 44 dias, indicam que essa fase já havia sido completada, tendo em vista que os valores de $\mathrm{pH}$ se mantiveram na neutralidade, decorrendo, portanto, 22 dias até a maturação completa. Paiva et al. (2010) constatou a superação média da fase ácida em um período de 30 dias. Segundo ele, esse período coincide com os picos de temperatura, que representam alta taxa de digestão. Jimenez e Garcia (1989), afirmam que os valores de pH entre 7 e 8 são indicadores de estabilização do composto, o que constata a eficiência da leira 01 , considerando as aferições de temperatura, para a qual não se obteve valores superiores aos $40^{\circ} \mathrm{C}$ após o alcance do pH próximo a 8 .

Apesar do acompanhamento tardio de outros parâmetros importantes, como o $\mathrm{pH}$ e a umidade, foi possível acompanhar o processo de degradação, sendo esse parâmetro essencial para identificar a existência de zonas suficientemente aeradas ou ainda a demanda por água ou inserção de materiais para manutenção da qualidade propícia à degradação dos resíduos.

A relação $\mathrm{C}: \mathrm{N}$ encontrada no composto final proveniente da leira 01 foi equivalente a 15:1. Conforme Kiehl (1998), a faixa de bioestabilização e de maturação é de 18:1 e 10:1, respectivamente. O valor encontrado seria, portanto, próximo ao intermediário e dentro dessa faixa, sinalizando o alcance da fase de maturação.

\section{Dados de Monitoramento da Leira 02}

A segunda leira foi iniciada no dia 20 de novembro de 2017 e finalizada em 08 de fevereiro de 2018. Os valores de pH encontrados na leira 02 estão na Tabela 04.

Tabela 04 - Dados de pH para a Leira 02

$\begin{array}{cc}\text { Período } & \text { pH } \\ 27 \text { nov/17 a 01 dez/17 } & 4,8 \\ \text { 04 dez/17 a 08 dez/17 } & 3,95 \\ 18 \text { dez/17 a } 22 \text { dez/17 } & 7,62 \\ 24 \text { jan/18 a } 26 \text { jan/18 } & 6,09 \\ 29 \text { jan/18 a } 02 \text { fev/18 } & 7,02 \\ \text { 05 fev/18 a 09 fev/18 } & 6,13\end{array}$


Joelma Lima Oliveira; Ana Beatriz Batista de Almeida;

Letícia Lacerda Freire; Monique da Silva Albuquerque;

Janderson Cabral Barbosa;

Mailodovinci de Sousa Pereira;

Uriel Pereira da Silva Barbosa

Nas semanas iniciais de desenvolvimento da Leira 02, através da aferição do $\mathrm{pH}$, foi possível observar o desenvolvimento da fase ácida durante os primeiros 30 dias. Conforme Cerri (2008), nesta etapa há atividades de fungos e bactérias que, ao degradar a matéria orgânica, produzem ácidos como resíduos que acabam predominando no sistema até a fase termófila. Ainda segundo o autor, após essa etapa, os ácidos passam por processo de oxidação, provocando uma elevação no $\mathrm{pH}$ até que haja a completa estabilização do composto. Tal afirmação foi observada durante o processo, pois a partir da quarta semana de operação da leira, os valores tenderam ao $\mathrm{pH}$ neutro, com pequenas oscilações, de forma a auxiliar na comprovação do término da mineralização dos resíduos, como também destacado para as medições realizadas na leira anterior.

As variações de temperatura para a leira 02 estão dispostas na Figura 07.

Figura 07 - Monitoramento das temperaturas para a Leira 02

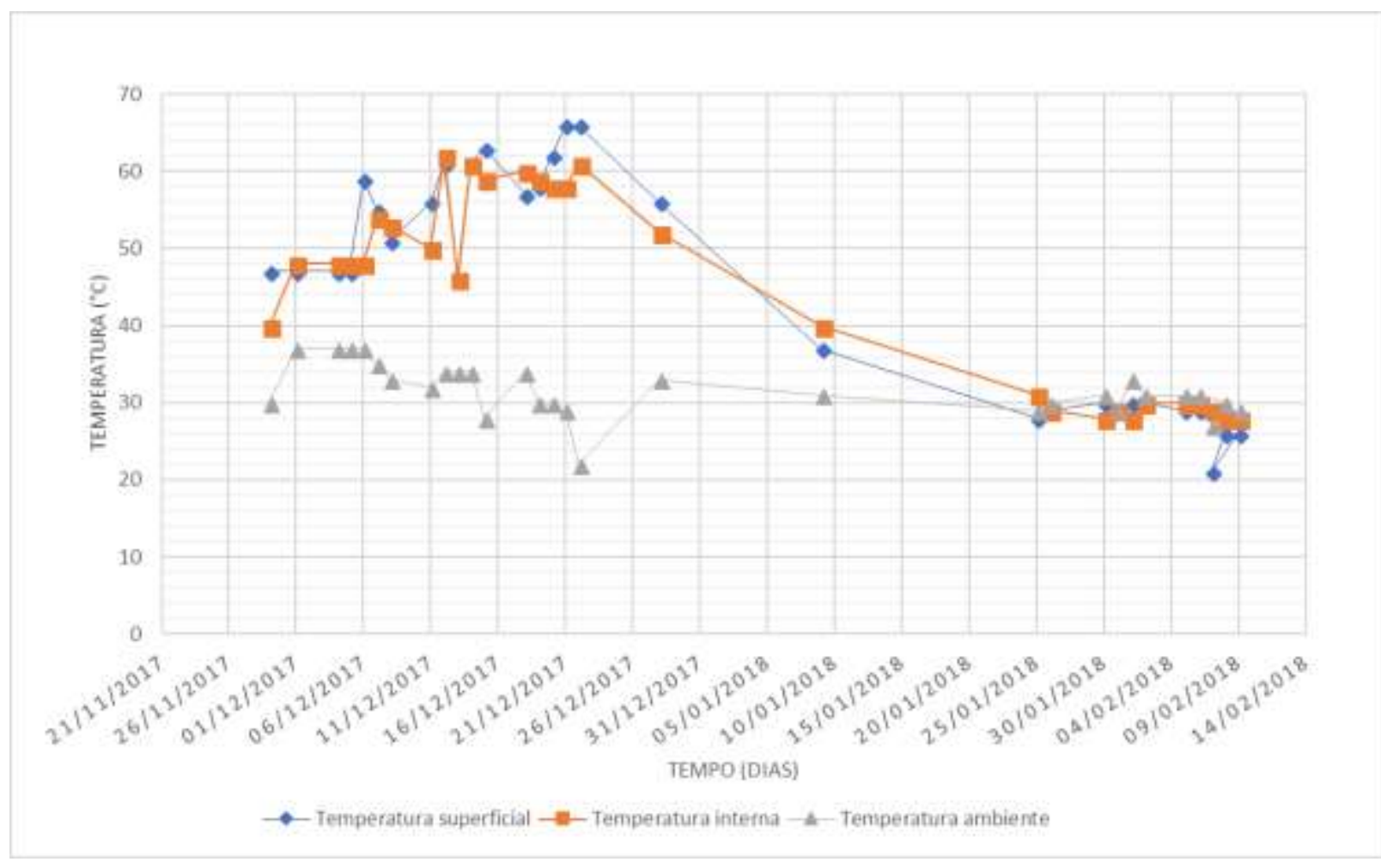

É observado o mesmo cenário indicado para a leira 01 , quanto à compatibilidade entre as variações de temperatura e de $\mathrm{pH}$. A temperatura máxima 
medida foi de $66^{\circ} \mathrm{C}$, sendo esse valor para a medida superficial de $61^{\circ} \mathrm{C}$ para a medida interna. De modo geral, a situação identificada não é comum para leiras de compostagem, por haver nas zonas internas um maior acúmulo de calor do processo de digestão. No entanto, a partir dos testes de umidade, foram identificadas zonas muito úmidas no interior da camada a ser compostada, retardando a elevação da temperatura resultante da atividade microbiana. Esse aspecto é de controle operacional podendo ser revertido pelo revolvimento das camadas e/ou adição de materiais que tem a capacidade de reter umidade, como a serragem ou palhas de grama seca.

Após o alcance de estabilização do composto, também indicado pela equiparação das temperaturas interna, externa e ambiente, foi realizado a análise da relação C:N para a qual se obteve um valor de 18:1, sendo esse mais um indicativo da fase de bioestabilização (KIEHL, 1998). Segundo Oliveira et al. (2008) é necessário adicionar ao composto fontes de nitrogênio, em virtude de que com a relação alta a contribuição de nutrientes para o sistemas de plantio tende a não ser efetiva. $\mathrm{O}$ acréscimo de materiais nitrogenados deve obedecer às sistemáticas de equilíbrio de mineralização e imobilização do nitrogênio, já descritas anteriormente.

\subsubsection{Dados de Monitoramento da Leira 03}

A terceira leira foi iniciada no dia 20 de dezembro de 2017 e está em operação. $O$ monitoramento está sendo realizado seguindo o mesmo padrão das análises das leiras anteriores.

A abrupta oscilação da temperatura, notada na Figura 08, pode ser justificada pela mudança nas condições ambientais do local. No começo da operação da leira 03, iniciou-se o período de chuvas na região, o que elevou consideravelmente a umidade do material, com isso, as zonas de aeração foram reduzidas, gerando a intensificação da atividade anaeróbia no sistema, ocasionando a proliferação de larvas e moscas e a liberação de odores desagradáveis.

Figura 08 - Monitoramento das temperaturas para a Leira 03 


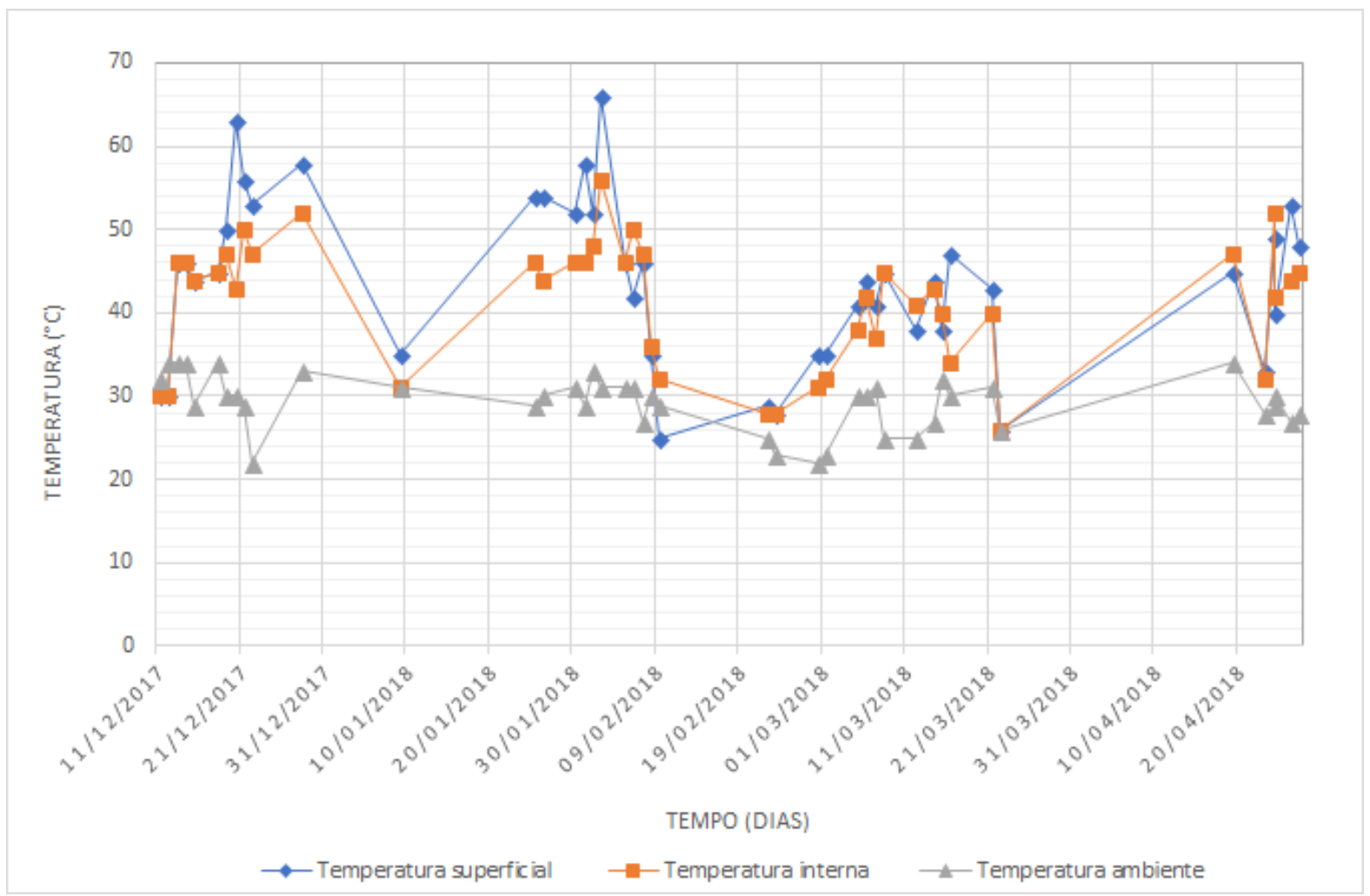

No sistema aderiu-se o formato de leira trapezoidal, devido ao quadro de distribuição de chuvas na região, com predominância de períodos secos. Porém, durante a execução e funcionamento do sistema de compostagem, as chuvas concentradas nos primeiros meses no ano geraram a desestabilização dos processos de decomposição, de modo que o revolvimento e a adição de materiais como a serragem não foram suficientes, para reverter a situação e melhorar os parâmetros monitorados.

Por esse motivo, a contribuição dos resíduos para a leira foi interrompida temporariamente, a sua formatação geométrica foi alterada, passando de trapezoidal para cônica, de forma a evitar maior acumulação de água provocada pelas precipitações. Além disso, o regime de revolvimento das leiras tornou-se mais frequente, com o objetivo de proporcionar maior aeração e, consequentemente, o aumento da velocidade de degradação dos resíduos. Ainda se fez necessário realizar o recobrimento das leiras com uma coberta de palha seca, com o objetivo de evitar maior acúmulo de umidade. A Figura 09 ilustra a adaptação do sistema. 


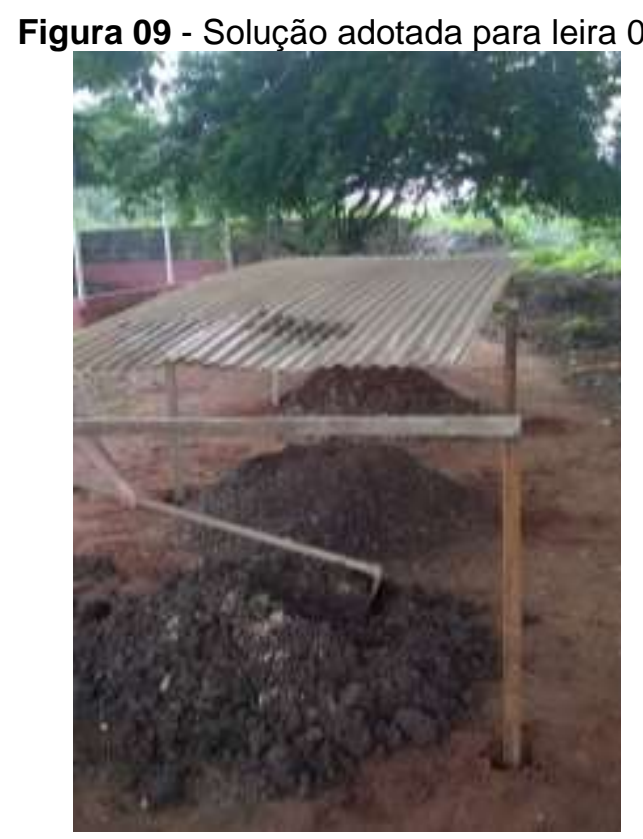

Os valores de $\mathrm{pH}$ encontrados referentes a leira 03 , encontram-se na Tabela 05.

Tabela 05 - Dados de pH para a Leira 03

$\begin{array}{cc}\text { Período } & \text { pH } \\ 18 \text { dez/17 a } 22 \text { dez/17 } & 4,54 \\ 24 \text { jan/18 a } 26 \text { jan/18 } & 5,80 \\ 29 \text { jan/18 a } 02 \text { fev/18 } & 6,73 \\ 05 \mathrm{fev} / 18 \text { a } 09 \mathrm{fev} / 18 & 6,29\end{array}$

Foi possível observar que a Leira 03 apresentou algumas variações no $\mathrm{pH}$, iniciando no $\mathrm{pH}$ ácido e tendendo à neutralidade, mas com um maior tempo até a superação da faze ácida, de forma a corroborar com o mencionado anteriormente para as leiras 01 e 02.

Destaca-se que no ano de 2018, de Janeiro a Abril, foram encaminhados para compostagem um total de $519 \mathrm{Kg}$ de resíduos sólidos orgânicos do restaurante acadêmico com a produção de $200 \mathrm{Kg}$ de composto.

Pelo tempo de estabilização do composto observado para as leiras concluídas, é possível afirmar que com uma manutenção adequada o tempo médio de 120 dias para maturação pode ser otimizado. 


\section{CONCLUSÃO}

O emprego da técnica de compostagem no Restaurante Acadêmico do IFCE Campus Juazeiro do Norte mostrou-se como uma alternativa simples, sem elevado ônus financeiro, mas que não dispensa a manutenção diária e/ou semanal quanto à verificação dos parâmetros indicadores de boa degradação, sendo a umidade e a temperatura os que demonstraram variações mais sensíveis. Apesar de algumas variações das condições ambientais foi possível realizar ajustes sem comprometer o resultado final do composto que pode ser considerado de boa qualidade.

Os principais desafios identificados na implantação e manutenção estão na obtenção de materiais adequados de trabalho, na segregação dos resíduos sólidos e na reduzida quantidade de colaboradores. Para atenuar o efeito das dificuldades encontradas foram adotados acessórios alternativos adaptados com materiais recicláveis, houve o aceite de doações de utensílios de trabalho, foram realizadas campanhas de educação ambiental na instituição e foi estimulada a participação de novos colaboradores como forma de oferta de estágio supervisionado no sistema de gestão ambiental.

O composto produzido atendeu as demandas das áreas verdes existentes na Instituição, mostrando-se também como uma ferramenta integração entre ações de ensino, pesquisa e extensão, assim como de educação ambiental.

O sistema de compostagem, possibilitou uma redução significativa do volume de resíduos orgânicos destinados a coleta municipal demonstrando ser uma ferramenta eficaz na busca pela qualidade ambiental, atenuando um dos principais impactos adversos gerados nas Instituições de Ensino Superior, a elevada geração de resíduos sólidos.

\section{REFERÊNCIAS}

ABNT. NBR 13591: Compostagem. Rio de Janeiro, p. 4. 1996.

ANDRADE, L.R.; LEAL, C.M.S.; OLIVEIRA, M.C.M. O Plano de Gestão dos Resíduos Sólidos do IFPB - Campus João Pessoa. In: Gestão integrada de resíduos: universidade \& comunidade. Luiza Eugênia da Mota Rocha Cirne, Paulo Roberto 
Megna Francisco, Soahd Arruda Rached Farias (Organizadores). v.1. Campina Grande: EPGRAF, 2018.

BRASIL. Compostagem doméstica, comunitária e institucional de resíduos orgânicos: manual de orientação. Ministério do Meio Ambiente. Centro de Estudos e Promoção da Agricultura de Grupo, Serviço Social do Comércio - Brasília, DF: MMA, 2017. ISBN: 978-85-7738-313-9.

BRASIL. Lei no 12.305, de 2 de agosto de 2010. Institui a Política Nacional de Resíduos Sólidos, altera a lei ํㅜ 9.605, de 12 de fevereiro de 1998 e dá outras providências.

CEARÁ. Plano Estadual de Resíduos Sólidos. Secretaria do Meio Ambiente SEMA. Fortaleza/CE, 2015. Disponível em: $<$ http://www.sema.ce.gov.br/attachments/article/43407/PERS\%20-\%20FINAL.pdf>. Acesso em 13 de maio de 2018.

CERRI, C.E.; OLIVEIRA, E.C.A.; SARTONI, R.H; GARCEZ, T.B. Compostagem. 2008. Disponível em: $<$ https://www.agencia.cnptia.embrapa.br/Repositorio/C ompostagem 000fhc8nfqz02wyiv80efhb2adn37yaw.pdf>. Acesso em: 16 mai. 2018.

EMPRESA BRASILEIRA DE PESQUISA AGROPECUÁRIA - EMBRAPA. Manual de métodos de análise de solos / organizadores, Guilherme Kangussú Donagema et al. — Dados eletrônicos. — Rio de Janeiro: Embrapa Solos, 2011. 230 p.

FERNANDES, F; SILVA, S.M.C.P. Manual Prático para compostagem de biossólidos - Finep. Programa de Pesquisa em Saneamento Básico - PROSAB/ Universidade Estadual de Londrina, 1999. Disponível em $<$ https://www.finep.gov.br/images/apoio-e-financiamento/historico-deprogramas/prosab/Livro Compostagem.pdf> Acesso em: 09. set. 2017.

HEBERTS, R.A.; COELHO, C.R.A.; MILETTI, L.C.; MENDONÇA, M.M. Compostagem de resíduos orgânicos: aspectos biotecnológicos. Revista Saúde e Ambiente/ Health and Environment Journal, v.6, n.1. jun. 2005.

INTERNATIONAL PLANT NUTRITION ISNTITUTE (IPNI). Manual Internacional de Fertilidade do Solo. $2^{\mathrm{a}}$ ed., rev. e ampl. Associação Brasileira para Pesquisa da Potassa e do Fosfato. Piracicaba: POTAFOS,1998. 
Joelma Lima Oliveira; Ana Beatriz Batista de Almeida; Letícia Lacerda Freire; Monique da Silva Albuquerque; Janderson Cabral Barbosa;

JIMÉNEZ, E. I.; GARCÍA, V. P. Instituto de Productos Naturales y Agrobiología de Canarias CSIC, Avda. Francisco Sanchez 3, 38206 La Laguna, Tenerife, Canary Islands, Spain. 1991.

JULIATTO, D.L; CALVO, M.J; CARDOSO, T.E. Gestão Integrada de Resíduos Sólidos para Instituições Públicas de Ensino Superior. Revista Gestão Universitária na América Latina - GUAL. V.4, N.3. p170 - 193. 2011. Disponível em: < http://www.redalyc.org/html/3193/319327512010/ > Acesso em: 17 jun. 2018.

KIEHL, E. J. Manual de Compostagem: maturação e qualidade do composto. Piracicaba, 1998.

LOPES SOBRINHO, O.P.; PEREIRA, A.I.S.; JÚNIOR, W.L.C; OLIVEIRA, L.S; XAVIER, R.S.; SILVA,J.J; SILVA,L.F.B.;; COSTA, D.A.S.; CANTANHEDE, E.K.P. Compostagem de resíduos orgânicos provenientes do restaurante do IFMA Campus Codó. Nativa: Pesquisas Agrárias e Ambientais, Mato Grosso, v. 5, n. 1, p.491-496, dez. 2017. Disponível em: <https://www.researchgate.net/p rofile/Oswaldo Palma/publication/322870687 Compostagem de residuos organico s provenientes do restaurante do IFMACampus Codo Composition of organic residues from restaurant of IFMACampus Codo/links/5a73aa0fa6fdcc53fe147f07/Compostagem-de-residuosorganicos-provenientes-do-restaurante-do-IFMA-Campus-Codo-Composition-oforganic-residues-from-restaurant-of-IFMA-Campus-Codo.pdf>. Acesso em: 16 mai. 2018.

MALHEIROS, R.; CAMPOS, A.G.; OLIVEIRA, D.G.; SOUZA, H.A. Utilização dos resíduos orgânicos por meio da compostagem como metodologia de ensino de gestão e educação ambiental. In: Anais V Congresso Brasileiro de Gestão Ambiental. Belo Horizonte - Minas Gerais. 2014.

NUNES, Maria Urbana Corrêa. Compostagem de Resíduos para Produção de Adubo Orgânico na Pequena Propriedade. Embrapa. Aracaju, 2009. Disponível em: <http://www.cpatc.embrapa.br/publicacoes 2010/ct 59.pdf >. Acesso em: 16 mai. 2018.

OLIVEIRA, E. C. A.; SARTORI, R. H.; GARCEZ, T. B. Compostagem. Universidade de São Paulo. Escola Superior de Agricultura Luiz de Queiroz. Programa de PósGraduação em Solos e Nutrição de Plantas. São Paulo, 2008.

PAIVA, E.C.R.; MATOS, A.T.; COSTA, T.D.R.; JUSTINO,E.A.; PAULA,H.M.

Comportamento do $\mathrm{pH}$ e da temperatura do material durante a compostagem de 
carcaça de frango com diferentes materiais orgânicos. In: I Congresso Brasileiro de Gestão Ambiental. Bauru - SP. Nov. 2010.

SILVA., M.A.; TAVARES.V.B.; Panorama e análise dos Resíduos Sólidos coletados em Instituições de Ensino Superior. Universidade Federal do Rio de Janeiro - RJ. 2018. 104p.

TAUCHEN, J.; BRANDLI, L. L. A gestão ambiental em instituições de ensino superior: modelo para implantação em campus universitário. Gestão \& Produção, São Carlos, v.13, n.3, p.503-515, 2006. 